\title{
Effects of different pretreatment methods on anaerobic mixed microflora for hydrogen production and COD reduction from palm oil mill effluent
}

\author{
Parviz Mohammadi, Shaliza Ibrahim, Mohamad Suffian Mohamad Annuar, Sean Law \\ Introduction
}

Dark fermentative hydrogen $\left(\mathrm{H}_{2}\right)$ production is one of several alternatives for non-renewable energy source like fossil fuels. $\mathrm{H}_{2}$ is viewed as a sustainable energy carrier with negligible or zero use of hydrocarbons and high-energy yield (122 kJ g_1) (Mu et al., 2006; Mohan et al., 2008; Özgür et al., 2010). In dark fermentative H2 production, carbohydrate-rich substrates are converted to $\mathrm{H}_{2}$ and other products by a number of different microorganisms. $\mathrm{H} 2$ yield from microbial fermentation is dependent upon microbial communities present, type of substrate and operational and environmental factors (i.e. organic loading rate, initial $\mathrm{pH}$, temperature, etc.) (Hallenbeck and Ghosh, 2009; Peintner et al., 2010). Bacterial species such as Clostridium, Escherichia coli and Enterobacter have been employed for $\mathrm{H} 2$ production (Chen et al., 2005; Chong et al., 2009a). These groups of microorganisms are ubiquitous in natural environments e.g. sediments, soil, wastewater sludge, compost etc. (Nandi and Sengupta, 1998; Das and Veziroglu, 2001; Cheong and Hansen, 2006; Zhu and Beland, 2006; Hu and Chen, 2007; Wang and Wan, 2009).

Pretreatment of sludge that is used for inoculum preparation in anaerobic system is one approach which helps to increase growth of bacteria and their $\mathrm{H}_{2}$ evolving activity (Kim et al., 2003; Zhu and Beland, 2006; Mohan et al., 2007). The three main stages for the microbial $\mathrm{H}_{2}$ production include (i) the selection of material containing bacterial population of interest; (ii) enrichment of these $\mathrm{H}_{2}$ producing bacteria and (iii) acclimatization of the bacteria to specific substrates (Zhu and Beland, 2006). Some reported pretreatment methods for enriching $\mathrm{H}_{2}$ producing bacteria include heat-shock, load-shock, acid, base, 2-bromoethanesulfonate acid (BESA), aeration, freezing and thawing, chloroform, and iodopropane (Hawkes et al., 2002; Mohan et al., 2008; Wang and Wan, 2008; Sompong et al., 2009). Several studies have been conducted to compare the influence of different pretreatment methods on the enrichment of $\mathrm{H}_{2}$ producing bacteria in anaerobic $\mathrm{H}_{2}$ production processes using various inoculants. Studies have shown that the application of heat-shock pretreatment method resulted in the 
highest $\mathrm{H}_{2}$ production rate (HPR) (Mu et al., 2007; Wang and Wan,

2008). Sompong and co-workers (2009) reported that the loadshock

treatment method was successfully applied in enriching

thermophilic $\mathrm{H}_{2}$-producing inocula and resulted in a maximum $\mathrm{H}_{2}$

production yield of $1.96 \mathrm{~mol} \mathrm{H} 2 / \mathrm{mol}$ hexose with a HPR of $11.2 \mathrm{mmol}$

$\mathrm{H}_{2} /(\mathrm{L} \cdot \mathrm{h})$. The highest $\mathrm{H}_{2}$ yield $\left(0.0317 \mathrm{mmol} \mathrm{g}_{-} 1 \mathrm{COD}\right)$ was obtained

by applying BESA pretreatment method among other methods

(Mohan et al., 2008). Cheong and Hansen (2007) on the other hand

reported that acid pretreatment method resulted in the highest

HPR. Nevertheless, most researchers used the heat-shock treatment

of sludge preparation in their experiments. Depending on the utilized bacterial source, they employed temperature values in the

range of $80 \mathrm{e} 121$ _C for an exposure time between 15 and $120 \mathrm{~min}$

(Lay et al., 1999, 2003; Ginkel and Sung, 2001; Logan et al., 2002;

Chang and Lin, 2004; Han and Shin, 2004). Nevertheless,

a decline in $\mathrm{H}_{2}$ production after one month operation of batch

experiment was observed for microbial populations initially

exposed to heat-shock treatment. Therefore, regular repetition of

sludge treatment with heat-shock was needed to avoid the aforementioned

problem (Duangmanee et al., 2007; Sompong et al.,

2009).

In other to remove $\mathrm{H}_{2}$ consuming bacteria from the inocula,

various methods for inocula preparation were applied based on the

physiological differences between $\mathrm{H}_{2}$ producing bacteria and $\mathrm{H}_{2}$

consuming bacteria (Zhu and Beland, 2006).

The main objectives of this study were to assess the efficiency of several pretreatment methods on anaerobic mixed culture for enriching $\mathrm{H}_{2}$ producing bacteria to increase biohydrogen production

and chemical oxygen demand (COD) removal efficiency

employing palm oil mill effluent (POME) as substrate. Simultaneous

$\mathrm{H}_{2}$ production and COD removal utilizing microbial process with

POME as a major substrate has been shown and optimized by Jamil and co-workers (Jamil et al., 2009).

\section{Materials and methods}

2.1. Palm oil mill effluent

The POME was collected from Felda Palm Oil Industry Sendirian

Berhad, Kuala Lumpur. Wastewater samples were immediately

transferred to the laboratory and stored in a cold room at 4 _C

before use. The characteristics of POME are summarized in Table 1.

2.2. Seed sludge

The bacterial population used as inoculumin the production of $\mathrm{H}_{2}$ 
from POME in this experiment was obtained from anaerobic treatment plant operated by Felda Palm Oil Industry Sendirian Berhad,

Kuala Lumpur. The sludgewas initially passed through amesh screen to remove fragments. The total volatile solids concentration of the sludgewas measured (27 g L_1) and total suspended solids (TSS)was measured (36 g L_1 1$)$.

\subsection{Pretreatment experiments}

In this study, experimentswere conducted to assess the influence of different pretreatment methods on anaerobic sludge in order to increase $\mathrm{H}_{2}$ production efficiency using POME as substrate. The sludge was sieved using grid size of $2.0 \mathrm{~mm}$ mesh to remove coarse matters and thenwashed with tapwater. Subsequently, itwas treated to disable $\mathrm{H}_{2}$ consuming bacteria and promote $\mathrm{H}_{2}$ production by one of the following methods: chemical pretreatment, acid hydrochloric pretreatment, heat-shock pretreatment, alkaline (base) pretreatment, freezing and thawing pretreatment.

The chemical pretreatmentwas conducted by adding $0.1 \%(\mathrm{v} / \mathrm{v})$ of chloroform into the sludge for $24 \mathrm{~h}$ at room temperature (Hu and Chen, 2007). The acid pretreatments were conducted by adjusting the $\mathrm{pH}$ of the sludge to 3.0 by adding $\mathrm{HCl}(6 \mathrm{~N})$ and maintained for $24 \mathrm{~h}$ and subsequently re-adjusted the $\mathrm{pH}$ to 5.5 by $\mathrm{NaOH}$ solution (2 N) (Chen et al., 2002; Sompong et al., 2009; Lee et al., 2009). The heat-shock pretreatment was conducted by heating the sludge to 100 _C for $1 \mathrm{~h}$ in thewater bath (Ginkel and Sung, 2001; Mohan et al., 2008). The base pretreatment was conducted by adjusting the $\mathrm{pH}$ of the sludge to 12 by adding $\mathrm{NaOH}(6 \mathrm{~N})$ and maintained for $24 \mathrm{~h}$ and subsequently re-adjusted the $\mathrm{pH}$ to 5.5 by $\mathrm{HCl}$ solution $(1 \mathrm{~N})(\mathrm{Cai}$ et al., 2004; Sompong et al., 2009). Freezing and thawing pretreatment was conducted by freezing the sludge to _ $10 \_\mathrm{C}$ for $24 \mathrm{~h}$ and then thawing it in a water bath at $30 \_\mathrm{C}$ until it reached room temperature (Cheong and Hansen, 2006). A control experiment using the sludge was also conducted without any pretreatment method. 2.4. Experimental set-up

Fig. 1 showed a schematic diagram of the serum bottle which served as a batch reactor in this study. Six $500 \mathrm{~mL}$ serum bottles were used for each run at $10 \% \mathrm{v} / \mathrm{v}$ sludge. The sludge samples in different serum bottles were subjected to the aforementioned pretreatments. After the pretreatments, POME was added into each bottle to obtain a final working volume of $200 \mathrm{~mL}$. The run was conducted at 35 _ 2 _C and an agitation rate of $120 \mathrm{rpm}$. The $\mathrm{pH}$ of the mixture was also adjusted to 5.5 _ 0.3 before initiating the batch test. In order to obtain an anaerobic condition for the bacteria, the entire serum bottle volume (headspace plus liquid)

Please refer to the full text 
was sparged with nitrogen for $15 \mathrm{~min}$ at a flow rate of $10 \mathrm{~mL} \mathrm{~s} \_1$.

The batch runs lasted for $72 \mathrm{~h}$ and all experiments were performed

in three replicates.

\subsection{Analytical methods}

The production of biogas was monitored via gas sampling at regular intervals. A syringe was used to extract measured volume of gas sample from each test bottles. The biogas composition was determined using a gas chromatograph (Perkin Elmer, AutoSystem GC) equipped with thermal conductivity detectors (TCD) and digital data acquisition system. $\mathrm{H}_{2}$ content was analyzed by GC-TCD fitted with a $1.5 \mathrm{~m}$ stainless steel column (SS350A) packed with a molecular sieve (80/100 mesh). The temperature values of the injection port, oven and detectorwere 80, 200, and 200 _C, respectively. Argon was used as a carrier gas at a flow rate of $30 \mathrm{~mL}$ min_1. The gas sample $(1 \mathrm{~mL})$ was injected in replicates. Other parameters, viz. chemical oxygen demand (COD), biochemical oxygen demand (BOD), $\mathrm{pH}$, total suspended solids (TSS), volatile suspended solids (VSS), total Kjeldahl nitrogen (TKN), were determined in accordance with the procedures described in the standard methods (APHA, 1999).

\section{Results and discussion}

\subsection{Effect of different pretreatments on $\mathrm{H} 2$ production}

The effect of various pretreatment methods on the enrichment of $\mathrm{H}_{2}$ evolving bacterial population and their $\mathrm{H}_{2}$ production efficiency by using POME as substrate was studied. Fig. 2 showed the variation of $\mathrm{H}_{2}$ production yield from the serum bottles inoculated with sludge subjected to different pretreatments and from the serum bottles without any pretreatment (control) during $72 \mathrm{~h}$ operation. Experimental results demonstrated the need for inoculum pretreatment for improved $\mathrm{H}_{2}$ generation by the microbial population as compared to control experiment. Heat-shock pretreatment was shown to be the most effective in enhancing the biological $\mathrm{H}_{2}$ production up to $48 \mathrm{~h}$ cultivation which appeared to coincide with the leveling of the COD reduction efficiency (see next section). The $\mathrm{H}_{2}$ yield from this method was $0.41 \mathrm{mmol} \mathrm{H} 2 / \mathrm{g}$ COD. $\mathrm{H}_{2}$ yield from control experiment was the lowest i.e. $0.12 \mathrm{mmol} \mathrm{H} 2 /$ $\mathrm{g}$ COD. The relatively low $\mathrm{pH}$ between 5.5 and 6.0 for entire duration of the batch process could have inhibited the growth of $\mathrm{H}_{2}$ consuming bacteria (Tang et al., 2008; Wang and Wan, 2009; Zhu et al., 2009; Chong et al., 2009b). H2 yield following the heatshock treatment was 3.4 times higher than that obtained in the control experiment. Among the pretreatment methods applied, the 
freezing and thawing method produced the lowest $\mathrm{H}_{2}$ yield

(0.19 mmol g_1 COD) whichwas approximately 58\% higher than the control. Although, $\mathrm{H}_{2}$ production was possible without any pretreatment (control), the application of different types of pretreatment resulted in a significant increase in $\mathrm{H}_{2}$ yield. The time profiles of the $\mathrm{H}_{2}$ production following the different pretreatments showed general maxima at $48 \mathrm{~h}$ cultivation. Thus, it is suggested that the harvesting of the pretreated sludge for the subsequent $\mathrm{H}_{2}$ production process should take place after not more than $48 \mathrm{~h}$. The cumulative $\mathrm{H}_{2}$ productions following different pretreatment methods are shown in Fig. 3. The highest cumulative $\mathrm{H}_{2}$ production $(8.89 \mathrm{mmol})$ was observed from the heat-shock pretreated sludge. The acid and base pretreatments showed similar influence on the cumulative $\mathrm{H}_{2}$ production but their $\mathrm{H}_{2}$ yields were lower than heat-shock treated sludge. The freezing and thawing pretreatment methods produced only $4 \mathrm{mmol} \mathrm{H} 2$ and had the least influence on $\mathrm{H}_{2}$ production among the different pretreatments.

The lag time before significant increase in $\mathrm{H}_{2}$ production varied between 8 (minimum) to 40 (maximum) h for heat-shock and freezing \& thawing pretreatment methods, respectively. The rest of the pretreatments and control exhibited lag time for $\mathrm{H}_{2}$ production in between this range. Cultures that were subjected to treatments using heat shock and base leveled off in their $\mathrm{H}_{2}$ production at $48 \mathrm{~h}$ whereas the rest were still showing increase albeit slower in their $\mathrm{H}_{2}$ evolution.

\section{Full text is available at :}

http://www.sciencedirect.com/science/article/pii/S0959652611001715 